\title{
A water-activated battery based on activated carbon
}

\author{
Dang Trang Nguyen, Kozo Taguchi \\ Department of Science and Engineering, Ritsumeikan University, Japan
}

\begin{tabular}{l} 
Article Info \\
\hline Article history: \\
Received Nov 25, 2018 \\
Revised Apr 19, 2019 \\
Accepted Apr 25, 2019 \\
\hline
\end{tabular}

\section{Keywords:}

Activated carbon

Air-cathode

Carbon nanotube

Paper-based

Potassium ferricyanide

Water-activated battery

\begin{abstract}
In this research, a novel property of activated carbon powder (AC powder) has been utilized to realize a disposable paper-based battery. AC powder was loaded on a 3D carbon paper substrate to make the anode. The cathode was integrated directly on the paper-based battery case by coating multiwalled carbon nanotube mixed with potassium ferricyanide on a side of a sheet of filter paper, the other side worked as a paper-based proton exchange membrane. This design provides a simple but practical disposable wateractivated battery. The developed battery generated the maximum power density of $10.4 \mu \mathrm{W} / \mathrm{cm}^{2}$ at the AC powder concentration of $17 \mathrm{mg} / \mathrm{cm}^{2}$. Although, the output power of the battery is low, it is made of low-cost and abundant materials, and therefore being able to scale up. The battery is a disposable and on-demand micropower generation activated anytime, anywhere by water.
\end{abstract}

Copyright (ㅇ 2019 Institute of Advanced Engineering and Science. All rights reserved.

\section{Corresponding Author:}

Kozo Taguchi,

Department of Science and Engineering,

Ritsumeikan University,

Kusatsu, Shiga, Japan.

Email: taguchi@se.ritsumei.ac.jp

\section{INTRODUCTION}

Nowadays, the energy and environmental crisis has become a serious problem, which may loom over next generations. Therefore, the exploration of every possible ways to generate energy through greener and cleaner processes becomes essential. Sustainable energy resources are believed to become the effective solution for this issue [1].

Activated carbon (AC) has been popularly utilizing for countless applications including purification of water [2] and biodiesel [3], heavy metal removal [4], capacitors [5], natural gas and biogas storage [6], improving hydrogen production [7]. Because AC has high surface area and adsorption capacity, plus it is abundant and low-cost. AC can be produced from almost all carbon-rich and inexpensive precursors (such as coconut shell, wood, saw dust) by physical activation or chemical activation [8]. AC has also been known for its catalyst support capacities in gas-solid reaction [9] and hydrogen generation from sulfur-iodine thermochemical water-splitting cycle [10].

In this research, we have discovered the property of electricity generation by $\mathrm{AC}$ powder: if $\mathrm{AC}$ powder is loaded in the anode compartment of a battery with the cathode and anode separated by a proton exchange membrane; then water is injected to the anode compartment, significant electric power is generated. Utilizing this property, we fabricated a paper-based water-activated battery (WAB), which used AC powder to generate electricity. To the best of our knowledge, this is the first study utilizing this property of AC powder to generate power. With the advantages of low cost, abundance, and sustainability, AC powder is a promising sustainable energy resource.

The paper-based design was used because paper has some unique properties including (i) inexpensiveness and abundance, (ii) convenience and biodegradability, and (iii) flexibility. The paperbased energy storage devices can facilitate disposable and stand-alone lab-on-chip systems [11], which have recently emerged as a new paradigm for clinical point-of-care (POC) diagnostics [12]. In this work, X-ray 
diffraction spectrogram (XRD) and scanning electron microscope (SEM) were used to characterize the AC powder and anode electrode. The performance of the WAB in various working conditions were investigated to understand its operating principle.

\section{RESEARCH METHOD}

\subsection{Materials}

Coconut shell-based activated carbon powder KD-PWSP (particle size of $6 \mu \mathrm{m}$ ) was purchased from UES Co., Ltd. Advantec \#6 filter paper (pore size of $3 \mu \mathrm{m}$ ) was purchased from Advantec Toyo Kaisha, Ltd. Multi-walled carbon nanotube (CNT) dispersion coating liquid N7006L (6.1 wt\% CNT) was purchased from KJ Specialty Paper Co., Ltd. Hydrophilic carbon paper C1-P2 (carbon fibre $50 \mathrm{wt} \%$ and cellulose fibre $50 \mathrm{wt} \%$ ) was provided by Azumi Filter Paper Co., Ltd. Potassium ferricyanide ( $\mathrm{PF}, \mathrm{K}_{3}\left[\mathrm{Fe}(\mathrm{CN})_{6}\right]$ ) was purchased from Wako Pure Chemical Industries Ltd. Nafion proton exchange membrane (PEM) was bought from AGC Engineering Co., Ltd.

\subsection{Paper-based WAB design}

Figure 1 shows the detail design of the developed paper-based WAB. The design represents the fusion of the art of origami and paper-based WAB. The battery case was fabricated based on a sheet of filter paper. Figure 1(a) shows the front and back side views with 4 parts indexed from (1) to (4), which were pre-divided by crease lines (dash line). The air-cathode was fabricated in part (1) by coating CNT mixed with $\mathrm{PF}\left(0.40 \mathrm{ml}\right.$ of $0.76 \mathrm{M} \mathrm{K}_{3}\left[\mathrm{Fe}(\mathrm{CN})_{6}\right]$ in $2 \mathrm{ml} \mathrm{CNT}$ solution) (F-CNT) on the back side by screen printing method (painting on masked areas). The front side served as a paper-based membrane. The whole battery case was then sprayed with hydrophobic solution (Water Proof Spray) to prevent water leaking to the battery case. A half-circle cut at the right-hand side of part (1) exposes the anodic electrical contact terminal.

In part (2), a hole was cut at the centre for water injection to the anode. The anode was attached to the middle area of part (2) using adhesive (3M-55 Spray Adhesive). Electrical contact for the anode were made by coating the CNT coating liquid using screen printing method. Part (3) had two half-circle cuts at the right and left-hand sides for the exposure of anodic and cathodic electrical contact terminals, respectively. Double-sided tape was attached to part (4) to fasten and clamp the whole battery when completely assembling. Then, part (1) was folded to part (2) flowing the crease line between the two parts. Parts (3) and (4) were folded around part (1) and (2) to assemble the complete battery as shown in Figure 1(b). It is further elaborated by A-A and B-B cross-section views. Figure 1(b) also shows the microscope image of the cross-section of the integrated membrane cathode with smooth continuity between the coated cathode and the membrane. The complete WAB had compact size of about $2 \mathrm{~cm} \times 2 \mathrm{~cm} \times 0.08 \mathrm{~cm}$ and light dry-weight of about $150 \mathrm{mg}$.
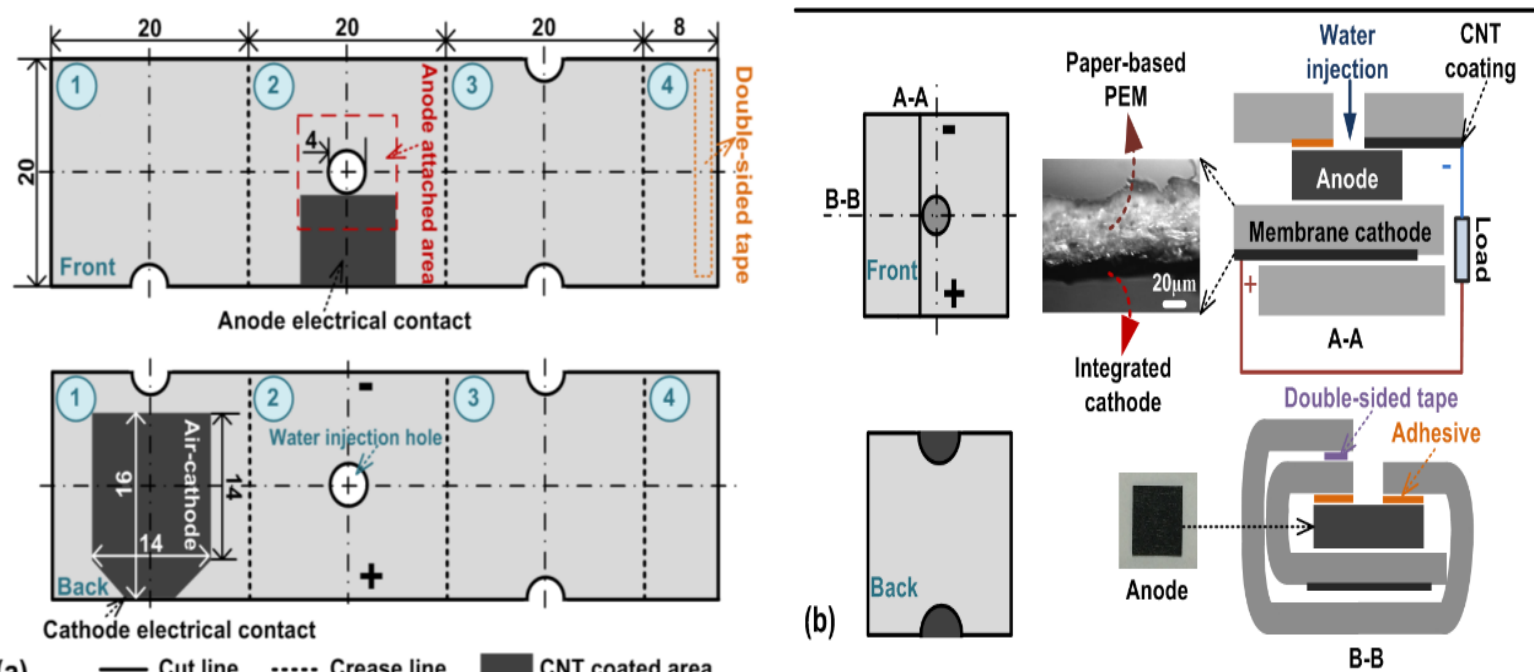

(a)

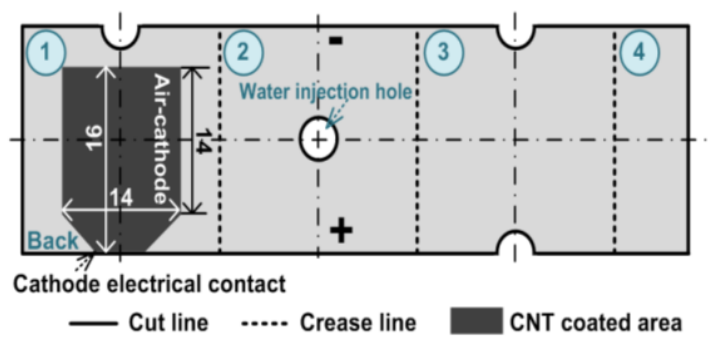

B-B

Figure 1. (a) The schematic diagrams of the front and back sides of the battery case. (b) The schematic diagrams of the front and back sides of the assembled WAB with its A-A and B-B cross-sections, the microscope image of the integrated membrane cathode cross-section, and the photo image of the anode 


\subsection{Anode fabrication and characterization}

To make the anode, AC powder was loaded on a hydrophilic 3D carbon paper substrate (C1-P2, $0.2 \mathrm{~mm}$ thickness) by immersing the carbon paper into the solution of AC powder ( $4 \mathrm{~g} \mathrm{AC} \mathrm{powder} \mathrm{mixed}$ with $10 \mathrm{ml}$ distilled water using a magnetic stirrer for $24 \mathrm{~h}$ ). After immersing the carbon paper for one minute, it was taken out for drying at $40^{\circ} \mathrm{C}$ for $30 \mathrm{~min}$. This is called as AC paper, which was cut to the size of $1 \times 1 \mathrm{~cm}$ to make the anode. The concentration of AC powder in this anode sample was about $17 \mathrm{mg} / \mathrm{cm}^{2}$.

\subsection{Experimental method}

Scanning electron microscopy (SEM, Hitachi S4300) was used to observe the surface of the carbon paper substrate and the AC powder. X-ray diffraction spectroscopy (XRD, X'Pert ${ }^{3}$ Powder PANalytical) was used to measure crystalline morphology of the AC powder, carbon paper, and AC paper. In all experiments, unless otherwise stated, we used the AC paper anodes with the AC powder concentration of $17 \mathrm{mg} / \mathrm{cm}^{2}$, the cathodes with the $\mathrm{PF}$ concentration of $0.40 \mathrm{ml}$ of $0.76 \mathrm{M} \mathrm{K}_{3}\left[\mathrm{Fe}(\mathrm{CN})_{6}\right]$ in $2 \mathrm{ml} \mathrm{CNT}$ solution, paper-based membrane, and tap water $(\mathrm{pH}=7)$. The experimental conditions were open air, at room temperature of $25^{\circ} \mathrm{C}$. Each experiment was conducted three times in identical conditions and the average result was presented in this paper. In addition, a $5 \mathrm{k} \Omega$ resistor was connected between the anode and cathode to discharge the WAB. After injecting $20 \mu \mathrm{l}$ tap water into the anode, the voltage over the resistor was monitored every $10 \mathrm{~s}$ by a data acquisition system (National Instruments USB-6210) via a customized LabVIEW interface on a computer.

\section{RESULTS AND DISCUSSION}

\subsection{Anode characterization}

SEM image of the 3D carbon paper C1-P2 is shown in Figure 2(a). Carbon fibres and cellulose fibres are interlaced to make a flexible 3D structure. The interconnection between the carbon fibres enables electrical conductivity for the carbon paper. The AC powder loaded on the anode is shown in Figure 2(b). It can be confirmed that the average particle size is $6 \mu \mathrm{m}$. In addition, the inset of Figure 2(b) shows honeycomb-like structure of nanoscale porosity on the surface of the AC powder. Due to this structure, the AC powder has large surface area [8].
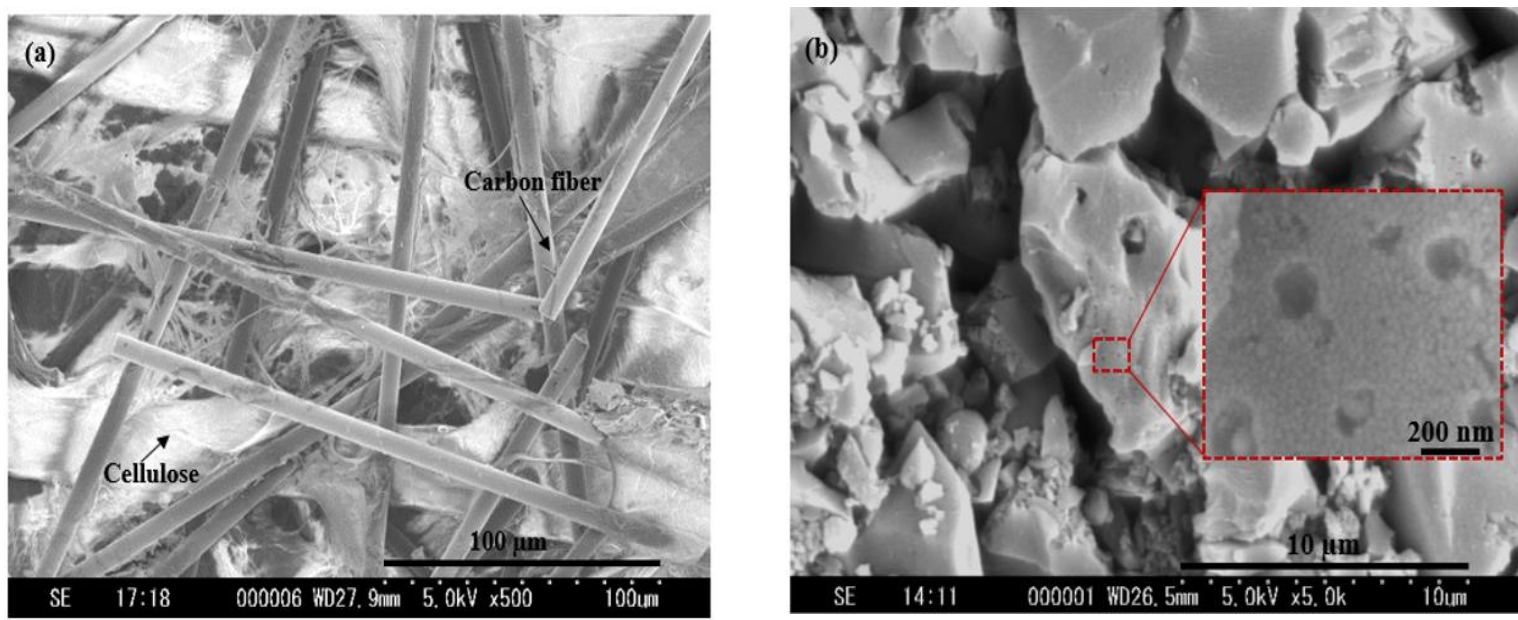

Figure 2. SEM images of (a) the 3D carbon paper C1-P2 and (b) the AC powder (the inset shows highly porous surface of the AC paper at high magnification)

Figure 3 shows the measured XRD data of the AC powder, carbon paper, and AC paper. The XRD pattern of the AC powder had strong and weak diffraction peaks at $2 \Theta=24^{\circ}$ and $44^{\circ}$, which show good agreement with the XRD data of other types of AC powder previously reported [13-15]. Obviously, the XRD pattern of the AC paper was the combination of the AC powder and carbon paper XRD patterns. Based on the diffraction pattern, it can be confirmed that no special contamination found in the fabricated anode, such as the peaks of any metal contamination. 


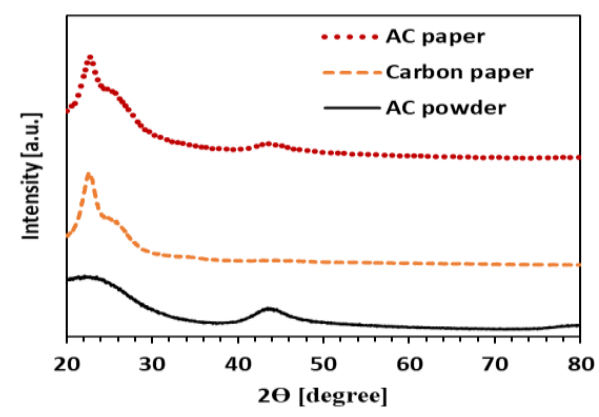

Figure 3. XRD pattern of the AC powder, carbon paper, and AC paper

\subsection{WAB characterization}

First, to confirm whether the AC powder is the main cause of electricity generation in the anode, we conducted an experiment using two anodic materials, which were the carbon paper only (without AC powder) and the AC paper (with AC powder). The experimental result is displayed in Figure 4. Obviously, the carbon paper anode generated negligible discharging voltage with the maximum voltage of $7 \mathrm{mV}$. Meanwhile, the AC paper anode generated much higher voltage with the maximum voltage of $180 \mathrm{mV}$. This result confirms that the AC powder was the main cause of electricity generation in the anode of the WAB.

Second, to evaluate the performance of the paper-based membrane, the commercial nafion PEM was used in the place of the paper-based membrane in the WAB. In this experiment, the nafion PEM was coated by F-CNT using the same method as used with the paper-based membrane. Then, it was used to replace part (1) in Figure 1. Figure 5 shows the performance of the nafion PEM in comparison with the fabricated paperbased membrane. In the case of using the nafion PEM the discharging voltage was significantly higher than that of the case using the paper-based membrane, the maximum output voltage of $300 \mathrm{mV}$ compared with $180 \mathrm{mV}$. Although the nafion PEM has better performance than the paper-based membrane, it is overqualified for disposable paper-based devices because it is expensive. Therefore, in this research we used the paper-based membrane to minimize the cost of the WAB.

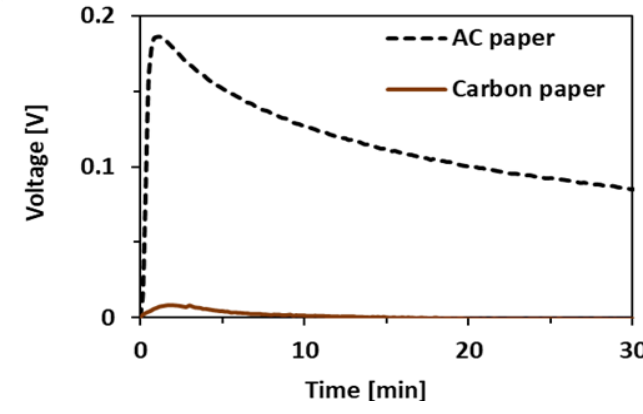

Figure 4. Discharging voltage of the WABs using carbon paper and AC paper anodes. The paper-based membrane and tap water were used in this experiment

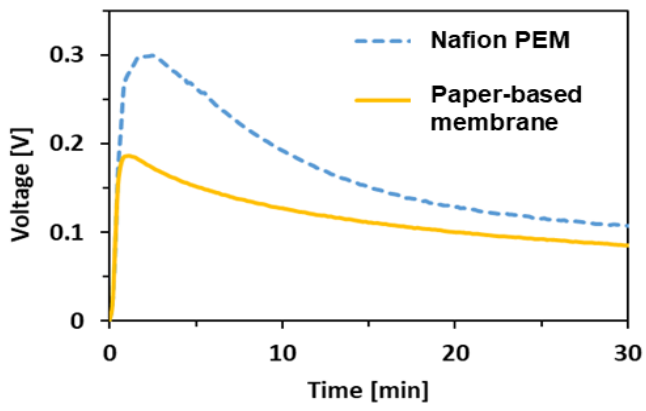

Figure 5. Performance comparison between the WABs using the fabricated paper-based membrane and the commercial nafion PEM. The AC anode and tap water were used in this experiment

Finally, the influence of the $\mathrm{pH}$ of water used for activation (activating solution) to the performance of the WAB was also investigated. We conducted an experiment with the WABs activated by acidic solution (0.1 M HCl, $\mathrm{pH}=1)$, basic solution $(0.1 \mathrm{M} \mathrm{NaOH}, \mathrm{pH}=13)$, and tap water $(\mathrm{pH}=7)$, respectively. The experimental result is shown in Figure 6. With the same volume of $20 \mu 1$ injecting to the anodes, the acidic solution generated the lowest voltage $(120 \mathrm{mV}$ at the maximum), while the basic solution generated the highest voltage $(320 \mathrm{mV}$ at the maximum), and the middle was the tap water $(180 \mathrm{mV}$ at the maximum). Based on this result, the $\mathrm{pH}$ of the activating solution is an important factor affecting the performance of the WAB. In this research, we used tap water with $\mathrm{pH}=7$ for all experiments because it is nontoxic and, in principle, easily accessible. 


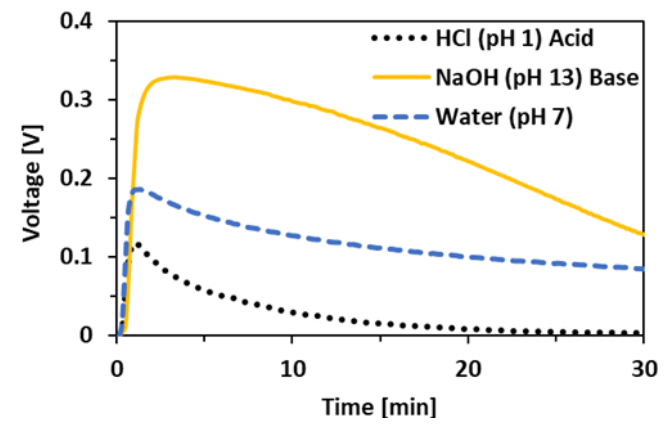

Figure 6. Performance comparison between the WABs activated by acidic solution $(0.1 \mathrm{M} \mathrm{HCl}, \mathrm{pH}=1)$, basic solution (0.1 M NaOH, $\mathrm{pH}=13)$, and tap water $(\mathrm{pH}=7)$, respectively. The AC anode and paper-based membrane were used in this experiment

\subsection{Power density}

To evaluate the power density of the WAB, different external resistors were used for discharging the battery. Figure 7(a) shows the maximum output voltage and the corresponding power density of the WAB as a function of the current density recorded at the given external resistors of $140 \mathrm{k} \Omega, 10 \mathrm{k} \Omega, 5 \mathrm{k} \Omega, 1 \mathrm{k} \Omega$, and $0.51 \mathrm{k} \Omega$. The discharging voltages are shown in Figure 7(b). At $1 \mathrm{k} \Omega$ external resistance, the maximum power density of $10.4 \mu \mathrm{W} / \mathrm{cm}^{2}$ was obtained. Based on this result, the internal resistance of the paper-based WAB was about $1 \mathrm{k} \Omega$.
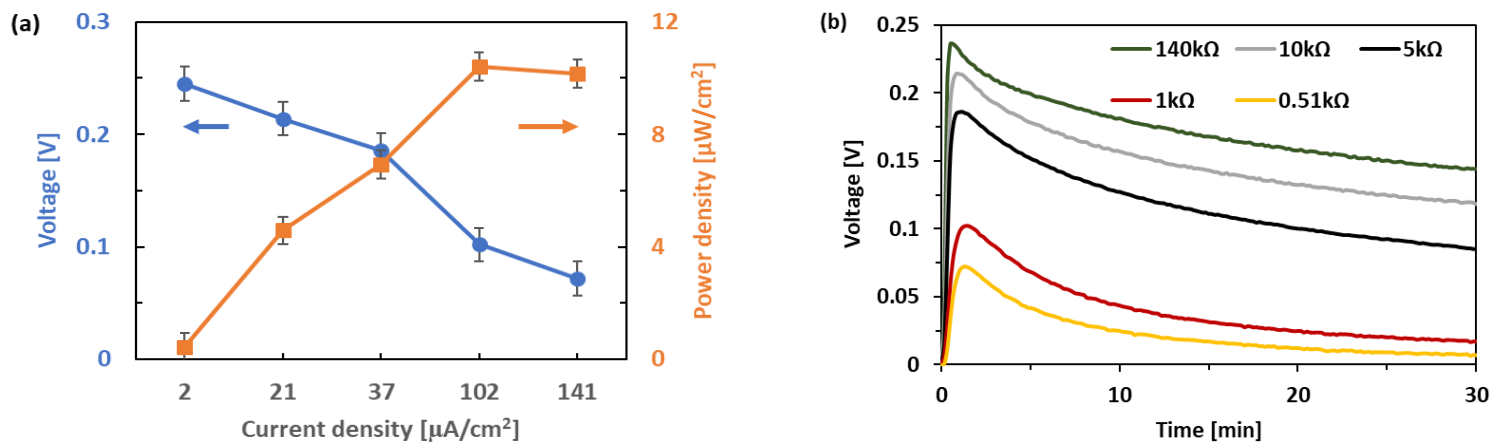

Figure 7. (a) Polarization curve of the maximum discharging voltage and the maximum power density as a function of the current density. (b) Output voltage discharged by some external resistors. The AC anode, paper-based membrane, and tap water were used in this experiment

\subsection{Discussion}

To explain for the experimental results shown in Figures 4, 5, and 6, we suppose that the operation of the WAB is as follows: electrons and protons are generated in the anode compartment after adding water to the AC anode to activate; the electrons go through the external circuit to the cathode while the protons migrate to the cathode through the membrane to complete the electrical circuit and keep the electro-neutrality in the system. Based on the result shown in Figure 5, the generation of the protons $\left(\mathrm{H}^{+}\right)$in the anode compartment can be confirmed because the nafion PEM can support only the penetration of protons. Due to the nafion PEM facilitated the migration of the protons from the anode to the cathode, the performance of the nafion PEM was better than that of the paper-based membrane. In addition, to explain the result shown in Figure 6, in acidic solution the concentration of $\mathrm{H}^{+}$is high, while that is low in basic solution. When the proton concentration in the anode compartment is high, it tends to hold back electrons, as a result, less electrons can reach to the cathode and therefore, the output voltage is decreased. This mechanism works in opposite fashion when the concentration of proton is low as in the situation of adding basic solution. Therefore, the basic solution generated the highest output, while the acidic solution generated the lowest output. 
Moreover, at the PF-preloaded air-cathode, the protons are reduced by oxygen in the air diffused in the cathode (1), however the slow reduction kinetic of plain oxygen limits this reduction reaction [16]. In addition to the reduction reaction by oxygen, PF is the main electron acceptor at the cathode (2) [16]. However, the reduction reaction by PF could not last forever; after a given time of operation all ferricyanide ions would be reduced. Therefore, the developed WAB is only suitable for disposable applications.

$$
\begin{aligned}
& \mathrm{O}_{2}+4 \mathrm{H}^{+}+4 \mathrm{e}^{-} \rightarrow 2 \mathrm{H}_{2} \mathrm{O} \\
& {\left[\mathrm{Fe}(\mathrm{CN})_{6}\right]^{3-}+\mathrm{e}^{-} \rightarrow\left[\mathrm{Fe}(\mathrm{CN})_{6}\right]^{4-}}
\end{aligned}
$$

The movement of electrons and protons explained above is similar to that of the biofuel cells [17]. We have not clearly understood the mechanism of how electrons and protons are generated by the AC powder when water is present. This characteristic may be related to the catalytic activity and nanoporous structure of the AC powder. It should be noted that the WAB presented here has a different mechanism from the traditional metal-based WAB, where water forms the electrolyte with ions produced by metal-based electrode reactions and a soluble salt [18]. Although at this stage, the WAB can generate low power density, it is worth to consider this type of WAB for further development because it is based on low-cost, abundant, and sustainable AC material, which is easy to access even at developing countries.

\section{CONCLUSION}

This paper focused on the demonstration of power generation by activated carbon in a paper-based WAB. The battery can instantly produce on-demand electricity activated by water. The developed WAB generated the maximum power density of $10.4 \mu \mathrm{W} / \mathrm{cm}^{2}$ at the AC powder concentration of $17 \mathrm{mg} / \mathrm{cm}^{2} \mathrm{loaded}$ on the 3D carbon paper-based anode. The paper-based WAB enables a low-cost power source that can potentially empower the next generation of self-powered paper-based diagnostic devices. For future studies, enough attention should be paid on further discovering the operating principle of this type of battery.

\section{ACKNOWLEDGEMENTS}

A part of this research was supported by AZUMI FILTERPAPER CO., Ltd.

\section{REFERENCES}

[1] N. L. Panwar, et al., "Role of renewable energy sources in environmental protection: A review," Renew. Sustain. Energy Rev., vol/issue: 15(3), pp. 1513-1524, 2011.

[2] B. J. Sánchez, et al., "Self-propelled activated carbon janus micromotors for efficient water purification," Small, vol/issue: 11(4), pp. 499-506, 2015.

[3] A. B. Fadhil, et al., "Purification of biodiesel using activated carbons produced from spent tea waste," J. Assoc. Arab Univ. Basic Appl. Sci., vol/issue: 11(1), pp. 45-49, 2012.

[4] M. Karnib, et al., "Heavy metals removal using activated carbon, silica and silica activated carbon composite," in Energy Procedia, vol. 50, pp. 113-120, 2014.

[5] M. Boota, et al., "Activated Carbon Spheres as a Flowable Electrode in Electrochemical Flow Capacitors," J. Electrochem. Soc., vol/issue: 161(6), pp. A1078-A1083, 2014.

[6] I. Esteves, et al., "Adsorption of natural gas and biogas components on activated carbon," Sep. Purif. Technol., vol/issue: 62(2), pp. 281-296, 2008.

[7] M. Hakamizadeh, et al., "Improving hydrogen production via water splitting over Pt/TiO 2/activated carbon nanocomposite," Int. J. Hydrogen Energy, vol/issue: 39(14), pp. 7262-7269, 2014.

[8] T. Lee, et al., "Activated Carbon Fiber -the Hybrid of Carbon Fiber and Activated Carbon," Rev. Adv. Mater. Sci, vol. 36, pp. 118-136, 2014.

[9] H. Jüntgen, “Activated carbon as catalyst support,” Fuel, vol/issue: 65(10), pp. 1436-1446, 1986.

[10] D. M. Ginosar, et al., "Commercial activated carbon for the catalytic production of hydrogen via the sulfur-Iodine thermochemical water splitting cycle," Int. J. Hydrogen Energy, vol/issue: 36(15), pp. 8908-8914, 2011.

[11] L. Ge, et al., "Photoelectrochemical lab-on-paper device based on an integrated paper supercapacitor and internal light source," Anal. Chem., vol/issue: 85(8), pp. 3961-3970, 2013.

[12] J. Hu, et al., "Advances in paper-based point-of-care diagnostics," Biosensors and Bioelectronics, vol. 54. pp. 585-597, 2014.

[13] C. G. Lee, et al., "Oxidation behavior of carbon in a coin-type direct carbon fuel cell," J. Electrochem. Soc., vol/issue: 158(4), pp. B410-B415, 2011.

[14] Y. Shu, et al., "Single and competitive adsorption of $\mathrm{Cd}(\mathrm{II})$ and $\mathrm{Pb}$ (II) from aqueous solution by activated carbon prepared with Salix matsudana Kiodz,” Water Sci. Technol., vol/issue: 74(12), pp. 2751-2761, Dec 2016. 
[15] Z. Xie, et al., "Production of biologically activated carbon from orange peel and landfill leachate subsequent treatment technology," J. Chem., vol. 2014, 2014.

[16] M. Rahimnejad, et al., "Microbial fuel cell as new technology for bioelectricity generation: A review," Alexandria Eng. J., vol/issue: 54(3), pp. 745-756, 2015.

[17] B. E. Logan, et al., "Microbial fuel cells: Methodology and technology," Environ. Sci. Technol., vol/issue: 40(17), pp. 5181-5192, 2006.

[18] J. R. Goldstein, et al., "Water activated battery," Google Patents, 2017.

\section{BIOGRAPHIES OF AUTHORS}

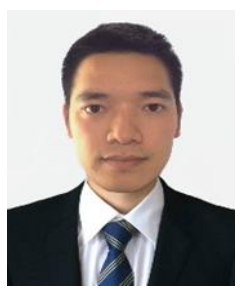

D. Trang Nguyen was born in Vietnam in 1986. He received the BS degree in 2009 from the Department of Telecommunication Systems Hanoi University of Science and Technology, Hanoi, Vietnam. After that he received the ME in 2011 from the Department of Electronics and Electrical Engineering, Dongguk University, Seoul, South Korea. From 2011 to 2014, he completed his $\mathrm{PhD}$ program in integrated science and engineering at Ritsumeikan University, Kyoto, Japan. After earning his $\mathrm{PhD}$, he was a quality assurance engineer at Takako Industries, Inc. from 2015 to 2017. Currently, he is a senior researcher at the Ritsumeikan Global Innovation Research Organization, Ritsumeikan University. His fields of interest include Biofuel Cells, Solar Cells, Biosensors, and Hydrogen Energy.

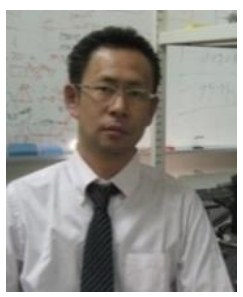

Kozo Taguchi was born in Kyoto, Japan, on December 18, 1968. He received the B.E., M.E., and Dr. Eng. Degrees in electrical engineering from Ritsumeikan University, Kyoto, Japan, in 1991, 1993, and 1996, respectively. In 1996, he joined Fukuyama University, Hiroshima, Japan, where he had been engaged in research and development on the optical fiber trapping system, semiconductor ring lasers and their application for optoelectronics devices, and polymeric optical waveguides for optical interconnection. In 1996-2003, he worked as an assistant and lecturer in Fukuyama University. In 2003, he moved to Ritsumeikan University, Shiga, Japan, and currently he is a professor of department of electric and electronic engineering. From 2006 to 2007, he was a visiting professor at University of St Andrews (Scotland, United Kingdom). From 2014 to 2015, he was a visiting professor at Nanyang Technological University (Singapore). His current research interests include cells trap, microfluidic cell-based devices, dye sensitized solar cell, biofuel cells, biosensors, and hydrogen energy. Dr. Taguchi is a member of the JJAP. 